\title{
Research and Design of Low Power Consumption of WSN Node in Agricultural Greenhouse
}

\author{
Jie Huang \\ College of Information and Communication Engineering, Hezhou University, Hezhou, China 542899 \\ huangjie0773@163.com
}

Keywords: Agricultural greenhouses; WSN node; Low power consumption; CC2530; Humidity sensor

\begin{abstract}
In order to effectively reduce the power consumption of WSN node in agricultural greenhouses, on the basis of considering the actual needs of the agricultural greenhouse WSN node, the low power consumption design of WSN node was studied. It expounds the design of low power consumption of WSN node in the agricultural greenhouse from two aspects of hardware design and software design. WSN node was tested. The test results show that the design of agricultural greenhouse WSN node has the advantages of low power consumption, good stability and high performance price ratio. It can accurately monitor the monitoring data in agricultural greenhouses. Its function and performance meet the design requirements, and it has good application prospects.
\end{abstract}

\section{Introduction}

Wireless sensor network is composed of a large number of ubiquitous, with communication ability and computing ability of tiny sensor nodes are densely deployed in unattended surveillance areas which can be completed independently according to the environment of intelligent autonomous control network system is a specific task [1,2]. Wireless sensor networks support a variety of network topology, which has the characteristics of flexible networking and convenient wiring. It has been widely used in agricultural greenhouses, forest fire monitoring, smart home and military applications [3,4]. Nodes in wireless sensor networks are generally powered by batteries. It has long been working in unattended environments. Due to the inconvenience of energy supply for wireless sensor nodes, with the energy consumption of sensor nodes, the nodes will fail. With the failure of the nodes, it will affect the stability and normal work of wireless sensor networks [5,6]. It is very important to reduce the power consumption of wireless sensor networks by adopting effective energy saving strategy. In this paper, the power consumption of WSN nodes in agricultural greenhouses is analyzed. From two aspects of hardware design and software design of WSN node, the low power design of WSN node is studied.

\section{Power Consumption Analysis of WSN Node}

The WSN node is composed of a sensor module, a computing storage module, a wireless communication module and a power module. The power module provides energy for WSN node. The sensor module, the computation storage module and the wireless communication module are the main energy consuming parts of the WSN node.

The power consumption of the sensor module is related to the frequency of the data collected by the sensor and the accuracy of the acquisition data [7]. If the data acquisition period is shorter and the precision of data acquisition is higher, it consumes more power consumption. In order to effectively reduce the power consumption of the sensor module, it can be combined with the practical application of WSN node to optimize the data acquisition cycle and the accuracy of the data acquisition. At the same time, the hardware design of sensor module is designed with low power consumption.

A computing memory module includes a processor and a memory. It is used to analysis, process and store data. The power consumption of computing memory module is closely related to the computing mode. If the amount of data is larger and the data storage is more frequent, it consumes 
more power consumption [8]. It is one of the effective ways to reduce the power consumption of the computing memory module to optimize the data calculation and data storage. Now, many processors support hibernation. When the processor is in a sleep state, its power consumption is very low. On the basis of meeting the design requirements, it can effectively reduce the power consumption of the computing memory module by calculating the intermittent sleep state.

Wireless communication module is used for communication between WSN nodes, which is the most energy consuming component in WSN nodes. The energy consumption of the wireless communication module includes the energy consumption of the transmitted data, the energy consumption of the received data, the energy consumption of the idle state and the energy consumption of the dormant state. The energy consumption of a wireless communication module is shown in Table 1.

Table 1 Energy consumption of wireless communication module

\begin{tabular}{cc}
\hline Wireless communication module status & Energy consumption[mW] \\
\hline Send data state & 14.76 \\
Receive data state & 12.32 \\
Idle state & 12.13 \\
Dormant state & 0.013 \\
\hline
\end{tabular}

According to the data in Table 1, in the energy consumption of wireless communication module, the energy consumption of the dormant state is relatively low, and the energy consumption of the other three states is relatively high. In order to effectively reduce the energy consumption of wireless communication module, it is necessary to effectively reduce the energy consumption of transmitted data and the energy consumption of received data in the wireless communication module. On the basis of meeting the needs of the design, it is necessary to minimize the use of wireless communication module to send data or receive data. When the wireless communication module does not receive data or send data, it should be switched off or let it into a dormant state to reduce energy consumption.

\section{Hardware Design of WSN Node in Agricultural Greenhouse}

The hardware design of the WSN node in the agricultural greenhouse mainly includes the hardware design of the sensor module, the hardware design of the computing storage module and the hardware design of the wireless communication module. The sensor module is used to collect the environmental data in the agricultural greenhouse. The computational memory module is used to analysis, process and store the data collected by the sensor module. Wireless communication module for communication between WSN nodes. The WSN node hardware structure is shown in Fig. 1.

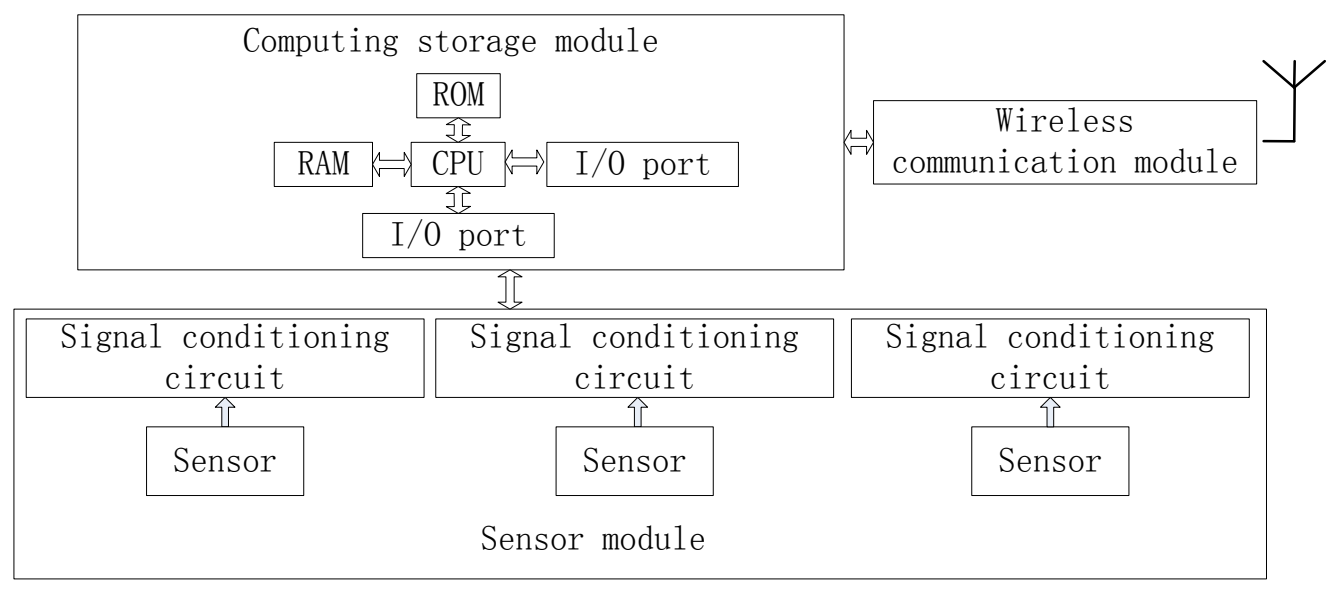

Figure 1. Finite WSN node hardware structure diagram 
The WSN node is mainly used to measure and control the environmental data in the agricultural greenhouse. In order to reduce the power consumption of WSN node, the following principles should be followed when designing the hardware of WSN node.

1) On the basis of meeting the needs of the design, it selects low power components to design WSN nodes.

2) In the hardware design of the computing memory module, the microprocessor should support hibernation.

3) In the hardware design of wireless communication module, the wireless communication module with low power consumption is selected.

After comprehensive consideration, the computing memory module and wireless commun ication module adopt CC2530 chip. CC2530 chip uses a low power 8051 microcontroller core. It has a variety of different operating modes. It has low power consumption. It is well suited for use in systems with ultra low power requirements. CC2530 chip has four different versions, which have $32 \mathrm{~KB}, 64 \mathrm{~KB}, 128 \mathrm{~KB}$ and $256 \mathrm{~KB}$ storage space. It contains a RF wireless transceiver that can be adapted to $2.4 \mathrm{GHz}$ IEEE 802.15 .4 . The wireless transceiver has high receiving sensitivity and anti-jamming performance.

In the WSN node of the agricultural greenhouse, the sensor module is mainly to collect the environmental data in the agricultural greenhouse. For example, it can be used to collect the temperature, humidity and light intensity values of agricultural greenhouses. In this design, the DHT22 sensor is used to collect the temperature and humidity in the agricultural greenhouse. The DHT22 sensor consists of a capacitive humidity sensor and a high precision temperature measuring element. It has the advantages of fast response speed, low power consumption, strong anti-interference ability and high cost performance ratio. The hardware circuit of DHT22 sensor and CC2530 chip is shown in Fig. 2.

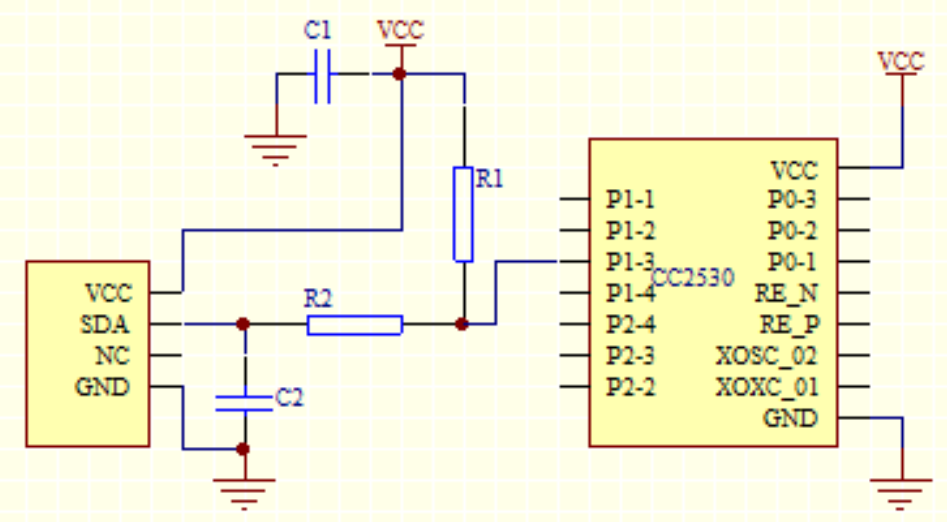

Figure 2. Finite Temperature and humidity detection circuit

\section{Software Design of WSN Node in Agricultural Greenhouse}

In the power consumption of the WSN node, it includes the power consumption of the sensor module, the power consumption of the computing memory module and the power consumption of the wireless communication module. The power consumption of wireless communication module is the most power consuming component in WSN node.

Software Design of Sensor Module. In the agricultural greenhouse, the sensor module is mainly to collect the temperature, air humidity, carbon dioxide concentration, light intensity and soil moisture value in the agricultural greenhouse. The power consumption of the sensor module is related to the frequency of the data collected by the sensor and the accuracy of the acquisition data. If the data acquisition period is shorter and the precision of data acquisition is higher, it consumes more power consumption. According to the characteristics of measured data in agricultural greenhouse, it is one of the effective ways to reduce the power consumption of the sensor module to design the data acquisition cycle and data acquisition precision. The value of temperature, air humidity and soil moisture in agricultural greenhouse is slowly changing. According to the 
characteristics of temperature, air humidity and soil moisture, the data acquisition cycle can be set up a little longer. Due to the influence of the external environment on the intensity of light in the agricultural greenhouse, the data acquisition cycle can be set up in a short time. The software design flow chart of the sensor module is shown in Fig. 3.

Software Design of Computing Memory Module and Wireless Communication Module. Wireless communication module is used for communication between WSN nodes. Wireless communication module is the most power consuming component in WSN node. On the basis of meeting the needs of the design, it is necessary to minimize the use of wireless communication module to send data or receive data. The computational memory module is used to Analysis, process and store the data collected by the sensor module. When the monitoring data does not change or the monitoring data changes little, the monitoring data is not sent by the WSN node. When the monitoring data has changed and the change range of the data exceeds a certain threshold, it is sent by the WSN node. In order to improve the accuracy of the monitoring data in the agricultural greenhouses, the value of monitoring data is measured by many times, and then the average value of monitoring data is calculated. The following algorithm is used to monitor the temperature of agricultural greenhouses. The algorithm is as follows.

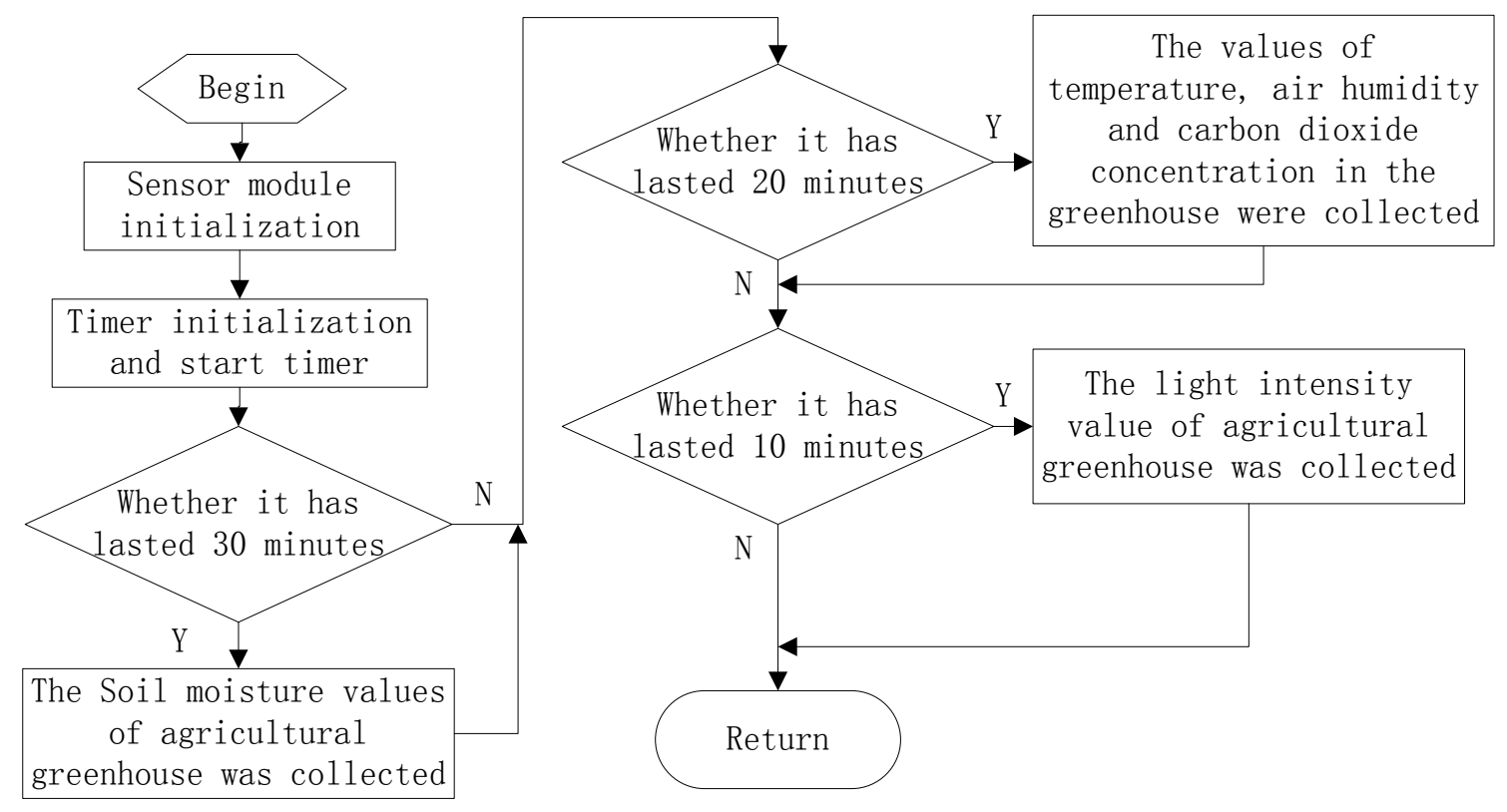

Figure 3. Finite Flow chart of software design of sensor module

1) The length of the array $A$ is defined as $n$, which is used to store the temperature in the agricultural greenhouse.

2) It assumes that the eighth collected temperature value is $W_{8}$. The last collected temperature value is stored in the array $\mathrm{A}[6]$. Compare the data $W_{I}$ with the temperature values stored in the array A, If the Eq.1 is established, the average temperature is calculated according to Eq.2. Clear the data in the array $\mathrm{A}$, and save the data $W$ to the array $\mathrm{A}[0]$. WSN node sends $W$ through wireless communication module.

$$
\begin{aligned}
& \left|W_{I}-A[j]\right| \geq \varepsilon \quad(\mathrm{j}=0,1, \cdots, \mathrm{I}-2) \\
& W=\frac{1}{I}\left(W_{I}+\sum_{j=0}^{I-2} A[j]\right) \\
& W=\frac{1}{n+1}\left(W_{I}+\sum_{j=0}^{n-1} A[j]\right)
\end{aligned}
$$

3) If the Eq.1 is not established, and the value I is greater than (n-1) or the value I is equal to 
(n-1), the average temperature is calculated according to Eq.3. Clear the data in the array A, and save the data $W$ to the array $\mathrm{A}[0]$. If the value $\mathrm{I}$ is less than (n-1), $W_{I}$ will be saved to the array $\mathrm{A}[\mathrm{I}-1]$.

4) Repeat 1) 3).

\section{System Test}

In order to test the function and performance index of WSN node, four WSN nodes are designed and fabricated. All nodes are installed in an agricultural greenhouse. According to the principle of hardware design and software design of WSN node, WSN node 1 is designed and finished. The hardware of WSN node 2 is exactly the same as that of WSN node 1 . However, the software design of WSN node 2 is inconsistent with the software design of WSN node 1. WSN node 3 and WSN node 4 are used as data receiving nodes. WSN node 1 uses the principle of software design in this paper to write the program, it is responsible for collecting the monitoring data in the agricultural greenhouse. When the monitoring data has changed and the change range of the data exceeds a certain threshold, the WSN node 1 transmits the data to the WSN node 3 through the wireless communication module. Every 8 minutes, the monitoring data of agricultural greenhouses were collected by WSN node 2. At the same time, the data is transmitted to the WSN node 4 through the wireless communication module. The test result shows that the power consumption of the WSN node 2 is much larger than the power consumption of the WSN node 1. According to the principle of hardware design and software design principle, the WSN node 1 has lower power consumption.

The accuracy of monitoring data is one of the important indexes of WSN node in agricultural greenhouses. Two sets of instruments are installed near the WSN node 1 and WSN node 2. It is used to measure the temperature, humidity and carbon dioxide concentration in the agricultural greenhouse. The test data of WSN node is shown in Table 2. As can be seen from table 2, the relative error of the monitoring data of WSN node 2 is not greater than $1.6 \%$. The relative error of the monitoring data of WSN node 1 is not greater than $3.1 \%$. The accuracy of the monitoring data of two WSN nodes is higher, which can meet the design requirements of the system.

Table 2 Test data of WSN node

\begin{tabular}{cccccc}
\hline WSN node & $\begin{array}{c}\text { Monitoring } \\
\text { data }\end{array}$ & $\begin{array}{c}\text { Monitoring } \\
\text { value }\end{array}$ & $\begin{array}{c}\text { Measured } \\
\text { value }\end{array}$ & $\begin{array}{c}\text { Relative } \\
\text { error }\end{array}$ & $\begin{array}{c}\text { Absolute } \\
\text { error }\end{array}$ \\
\hline \multirow{2}{*}{ WSN node } & Light intensity & $31000[\mathrm{lux}]$ & $31500[\mathrm{lux}]$ & $1.6 \%$ & $500[\mathrm{lux}]$ \\
1 & Soil moisture & $62 \%$ & $64 \%$ & $3.1 \%$ & $2 \%$ \\
& Temperature & $22.3\left[{ }^{\circ} \mathrm{C}\right]$ & $22.4\left[{ }^{\circ} \mathrm{C}\right]$ & $0.45 \%$ & $0.1\left[{ }^{\circ} \mathrm{C}\right]$ \\
& Air humidity & $76 \%$ & $78 \%$ & $2.6 \%$ & $2 \%$ \\
WSN node & Light intensity & $32000[\mathrm{lux}]$ & $31700[\mathrm{lux}]$ & $0.9 \%$ & $300[\mathrm{lux}]$ \\
2 & Soil moisture & $63 \%$ & $64 \%$ & $1.6 \%$ & $1 \%$ \\
& Temperature & $22.3\left[{ }^{\circ} \mathrm{C}\right]$ & $22.4\left[{ }^{\circ} \mathrm{C}\right]$ & $0.45 \%$ & $0.1\left[{ }^{\circ} \mathrm{C}\right]$ \\
& Air humidity & $77 \%$ & $78 \%$ & $1.3 \%$ & $1 \%$ \\
\hline
\end{tabular}

\section{Conclusions}

In this paper, the low power consumption design of WSN node in agricultural greenhouses is studied and analyzed. It designs the low power consumption of WSN node from two aspects of hardware design and software design. In the hardware design, the CC2530 chip and other low power components are used to design the sensor module, the computing storage module and the wireless communication module of the WSN node. In the software design, according to the characteristics of the measured data in the agricultural greenhouse, the collection period and the acquisition precision are set up for different monitoring data. Through the analysis and processing of monitoring data, reduce the use of wireless communication module to send data or receive data. 
The WSN node has the advantages of low power consumption, good stability and high performance price ratio. It has a good application prospect.

\section{Acknowledgement}

This work was financially supported by the National Natural Science Foundation of China (Grant No. 6154055).

\section{References}

[1] H.B. Yu, W. Liang and P. Zeng: Intelligent Wireless Sensor Network System (Science Press, Chinese 2013), P.135. (In Chinese)

[2] Y. Zhang, F.N. Liu and L. Cao: Instrument Technique and Sensor, Vol. 45 (2015) No.7, p.41. (In Chinese)

[3] L.L. Yan and J.G. Zhao: Chinese Journal of Power Sources, Vol. 38 (2014) No.10, p.1898. (In Chinese)

[4] X.Q. Wang, Y.J. Ou and N.L. Huang: Design and Implementation of ZigBee Wireless Sensor Network (Chemical Industry Press, Chinese 2012), p.76. (In Chinese)

[5] Z.J. Chen, Q.Y. Guo and Z. Shi: Mobile Communications, Vol. 42 (2012) No.16, p.76. (In Chinese)

[6] Y.S. Miao, H.W. Wu, H.J. Zhu and F.F. Li: Computer Engineering and Design, Vol. 35 (2014) No.8, p.2723. (In Chinese)

[7] Y. Chen, D.X. Yang, H. Guo, K.D. Wang and L. Chen: Instrument Technique and Sensor, Vol. 42 (2012) No.7, p.107. (In Chinese)

[8] F. Zhao and W.H. Xu: Electronic Design Engineering, Vol. 20 (2013) No.11, p.144. (In Chinese)

[9] L.M. Sun, J.Z. Li, Y. Chen and H.S. Zhu: Wireless Sensor Network (Tsinghua University press, Chinese 2005), p.116. (In Chinese)

[10] B.M. Li: Mechanical \& Electrical Technology, Vol. 36 (2013) No.2, p.84. (In Chinese) 